\title{
LA BOLSA DE LA HABANA, EL MERCADO MUNDIAL DE AZÚCAR Y LAS FLUCTUACIONES DE LA ECONOMÍA CUBANA, 1910-1959*
}

\author{
JAVIER MORENO LÁZARO
}

Universidad de Valladolid $^{\mathrm{a}}$

\begin{abstract}
The Havana Stock Exchange, global sugar market and fluctuations of the Cuban economy,
\end{abstract}
\begin{abstract}
This paper presents the course taken by the Cuban economy from the early twentieth century until the outbreak of the Revolution, seen from the perspective of what happened in the stock market. I have therefore prepared an index of Havana Stock Exchange listings which shows strong dependence on what happened in the sugar market, particularly in sugar exports. However, my research highlights the weakness of this institution, conceived more as an instrument of speculative enrichment rather than one of financing, the evolution of which reveals the fragility of the Cuban economy and particularly the poor development of its capital markets.
\end{abstract}

Keywords: Cuban Economic History, Financial History, Stock Market, sugar market, capitals market

JEL Classification: H63, N26, N46, O54, G12

* Received 20 March 2012. Accepted 27 November 2012. Este trabajo, primer avance de una investigación más ambiciosa y prolongada en el tiempo, es el resultado de mi pertenencia al proyecto de investigación en Geohistoria, dirigido por Reinaldo Funes Monzote, de la Fundación Antonio Jiménez Núñez de La Habana. No habría emprendido esta investigación sin el aliento y la asesoría de mi maestro en tantas cuestiones: Francisco Comín Comín. En la documentación de este trabajo en La Habana gocé de la inestimable ayuda de Jorge Macle (así como de Bertha, Julio, Marisol y Marlaine) en al Archivo Histórico Nacional y de Nancy Machado en la Biblioteca Nacional José Martí. No puedo olvidar el apoyo de mis amigos habaneros Yoelvis Romero, Fernando Camaaño y Hanoy Delgado. Alfonso Herránz me ayudó en situaciones de apuros estadísticos. Los dos sagaces evaluadores me obligaron, con sus minuciosos y agudos comentarios, a mejorar mis argumentaciones con resultados más que tangibles. A todos ellos, muchas gracias.

a Departamento de Fundamentos del Análisis Económico e Historia e Instituciones Económicas, avenida Valle Esgueva, 6 · 47011, Valladolid. 


\section{RESUMEN}

En este trabajo se presenta una aproximación a la trayectoria de la economía cubana, desde comienzos del siglo XX hasta el estallido de la Revolución, vista desde la perspectiva de lo sucedido en el mercado de acciones. A tal fin, he construido un índice de cotización de la Bolsa de La Habana, que muestra una fuerte dependencia con lo sucedido en el mercado azucarero, en particular con las exportaciones de azúcar. No obstante, mis investigaciones revelan la debilidad de esta institución, concebida más como un instrumento de enriquecimiento especulativo que de financiación, cuya evolución desvela la propia fragilidad de la economía cubana y, particularmente, el escaso desarrollo de su mercado de capitales.

Palabras clave: Historia Económica de Cuba, Historia Financiera, Bolsa, mercado azucarero, mercado de capitales

\section{INTRODUCCIÓN}

La Bolsa de La Habana es la Cenicienta de la historia financiera de Cuba ${ }^{1}$. En los análisis sobre la evolución económica del país a lo largo de la primera mitad del siglo XX solo se encuentran referencias de soslayo a lo sucedido en el parqué ${ }^{2}$.

Tampoco los contemporáneos repararon en ella, ni siquiera en vísperas de la Revolución, cuando mayor inquietud académica y política hubo por discernir las causas del atraso insular, tan tenaz e inútilmente denunciado por los responsables económicos de la joven República ${ }^{3}$. El exiliado español Julián Alienes, un brillante keynesiano, es el único que le prestó alguna atención; pero reducida a la evolución de la cotización de la deuda pública, prioritaria en sus intereses (y en los de los gestores económicos del país) por sus implicaciones en las cuentas del sector exterior ${ }^{4}$. Resulta también llamativo que en los estudios apologéticos de la economía del batistato realizados en el exilio tampoco figure noticia alguna sobre ella ${ }^{5}$.

1 Gutiérrez (1952); Zuaznábar (1986).

Wallich (1950).

3 Wolter (1937, p. 8); Zanetti (1989). En el capítulo dedicado al sistema financiero del muy socorrido informe elaborado por el historiador económico Francis Adams Truslow (1951) por encargo del Banco Mundial no hay la menor alusión a ella. Por referir otras fuentes similares, redactadas por observadores estadounidenses, a las que se les ha otorgado algún crédito, tanto el estudio confeccionado por Foreign Policy Association (1935) como la monografía de Porter (1899), primera semblanza de la Estructura Económica de la Gran Antilla después de la firma del Tratado de París, guardan el mismo silencio.

4 Alienes (1942).

5 El democristiano José Illán (1963), quien fuera uno de los padres del mito de la arcadia económica republicana y subsecretario de Hacienda del Gobierno Revolucionario de enero de 1959 
Desde luego, este silencio no obedece a la indolencia de los autores citados. Si la institución pasó inadvertida a unos y otros fue a causa de su escasa entidad ${ }^{6}$. Pero no es menos cierto que su conocimiento puede ayudar a desvelar la influencia de los movimientos de capitales y de los cambios en el mercado mundial (sobre todo en el de azúcar) en las finanzas cubanas, un capítulo al que la historiografía sí ha atribuido la importancia que se merece ${ }^{7}$.

El propósito de este trabajo es efectuar un primer recorrido por la Historia Económica de la República con la Bolsa de valores como argumento. Persigo desvelar la manera en que la sumisión a los dictados del mercado azucarero por parte de una economía monoexportadora incidió en sus fluctuaciones económicas y determinó su desarrollo ${ }^{8}$. Entiendo que la Bolsa constituye un excelente barómetro para realizar este ejercicio.

\section{CONSTRUCCIÓN Y DETERMINANTES DEL ÍNDICE DE COTIZACIONES}

A consecuencia de ese mencionado desdén hacia la institución, hubo que esperar hasta 1950 a que el departamento de Econometría de la Junta de Economía Nacional elaborase un primer un índice retrospectivo, muy tosco, de los valores bursátiles que arrancaba en 1942, considerando media docena de títulos 9 .

En ausencia de series más prolongadas y fiables, he confeccionado un índice Laspeyres alternativo considerando la media anual de las cotizaciones (excluidos dividendos) de cierre de cada mes. El índice comprende la cotización de 23 compañías desde 1910 de objetos sociales diversos (empresas ferroviarias, manufactureras no alimenticias, navieras, pesqueras, energéticas, aeronáuticas, azucareras y financieras). He efectuado las ponderaciones, convenientemente ajustadas a la entrada y salida de nuevos valores, con arreglo al capital nominal de cada uno de ellas. Para ello me he servido de los libros de Actas de Cotizaciones, custodiados en el Archivo Nacional de Cuba (en adelante, ANC). La consulta de esta documentación me ha permitido elaborar también sendos índices de la cotización de las obligaciones y de la deuda pública interior a diez y más años emitida por el Gobierno.

El estudio de las condiciones de financiación bursátiles de las empresas y del Estado cubanos no puede obviar lo sucedido en el mercado de capitales

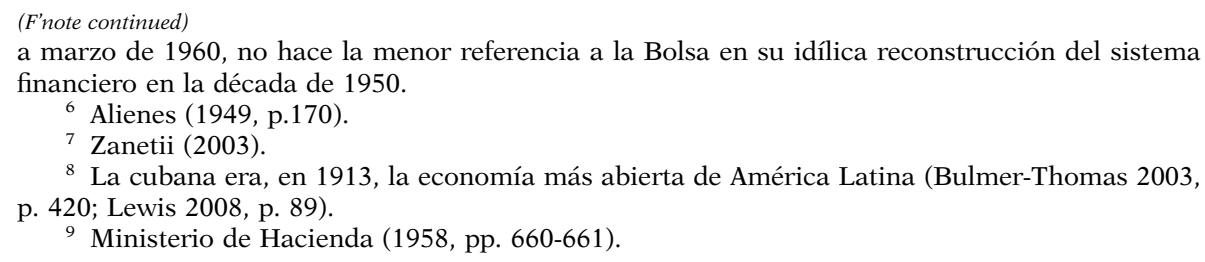

8 La cubana era, en 1913, la economía más abierta de América Latina (Bulmer-Thomas 2003, p. 420; Lewis 2008, p. 89).

9 Ministerio de Hacienda (1958, pp. 660-661). 


\section{GRÁFICO 1}

COTIZACIÓN DE LOS VALORES NEGOCIADOS DE LA BOLSA DE LA HABANA, 1910-1959 (EN NÚMEROS ÍNDICES BASE 1950)

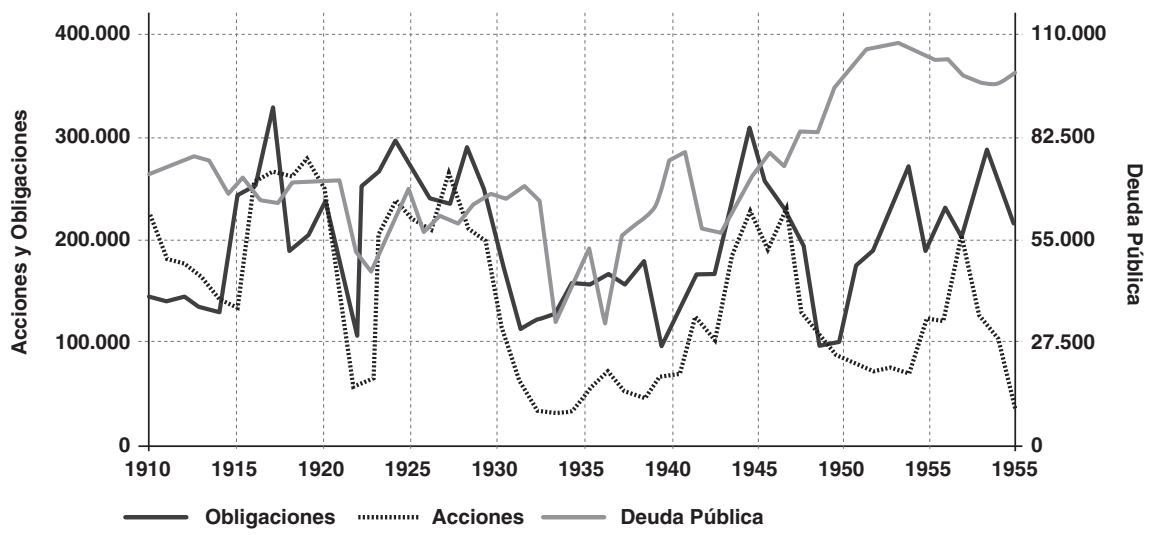

Fuente: ANC, Bolsa de La Habana, Actas de Cotización.

estadounidense, por lo que he completado mis cálculos con los de las cotizaciones de los valores de ese país en Wall Street, obtenidas de la prensa habanera y neoyorquina. La metodología en la elaboración de estos nuevos índices es idéntica a la expuesta.

En los Gráficos 1 y 2 presento los resultados de mis cálculos. La consideración de los datos representados en el Gráfico 3 revela una fuerte dependencia de lo sucedido en el mercado del azúcar en Estados Unidos. De hecho, el grueso de las grandes firmas azucareras cubanas (en su mayor parte, en manos del empresario asturiano Rionda) se negoció en la Bolsa de Nueva York, y no en la de La Habana.

Constatada esta relación entre mercado azucarero y capitalización bursátil, en los párrafos que siguen analizo la evolución del índice, con arreglo a los condicionantes citados, así como a los niveles de actividad de la economía cubana, su posición exterior y el montante del déficit público ${ }^{10}$.

\section{LOS INICIOS (1857-1913)}

En agosto de 1857, Francisco Calderón y Kessel, marqués de Casa Calderón, activo miembro de la Sociedad Económica de Amigos del País, y Luciano García Barbón, jurista especializado en la defensa de los intereses

${ }^{10}$ En este ejercicio, me he servido de las reflexiones y evidencias empíricas aportadas por Zanetti (2003). 


\section{GRÁFICO 2}

COTIZACIONES DE LAS BOLSAS DE LA HABANA Y DE NUEVA YORK, 1910-1959 (EN NÚMEROS ÍNDICES BASE 1950)

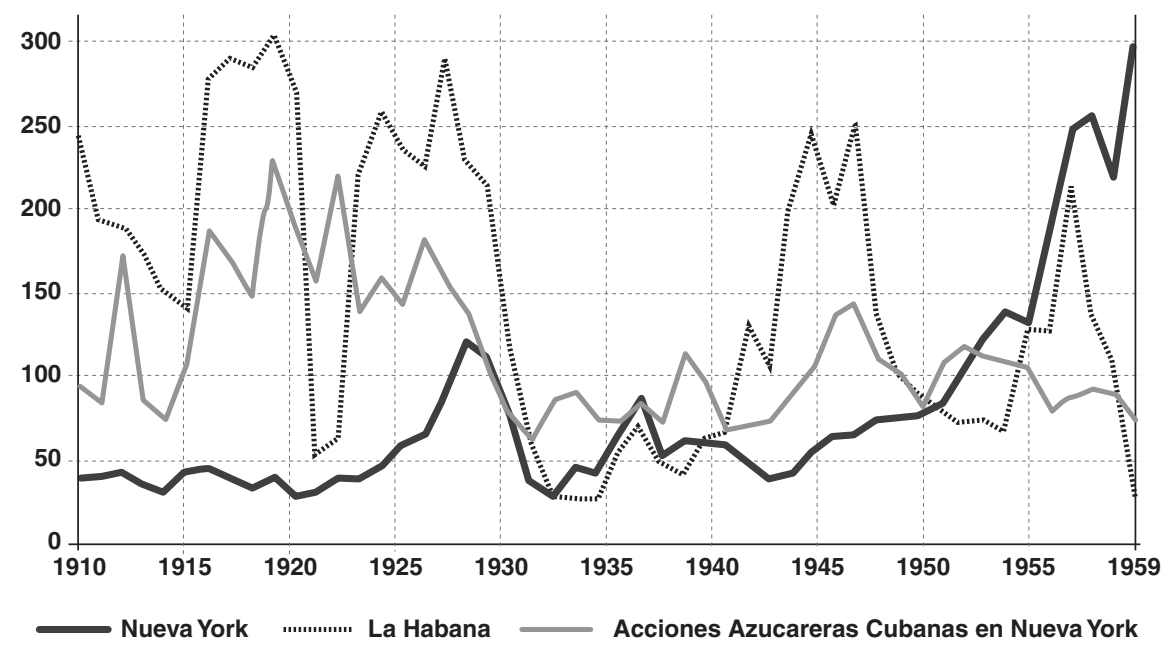

Fuente: ANC, Bolsa de La Habana, Actas de Cotización y New York Tribune, Nueva York (1910-1959).

patrimoniales de los hacendados cubanos, solicitaron licencia para crear una Bolsa de Valores en La Habana, proyecto en el que venían trabajando desde $1855^{11}$. El permiso no llegó de O’Donnell, ministro de Guerra y Ultramar, hasta 1859, cuando se avino a permitir su funcionamiento, eso sí, con carácter provisional (sic) y sin grandes miras. Madrid, a regañadientes, consintió dotar a la isla de una institución que acrecentaba su soberanía financiera ${ }^{12}$. La crisis de 1857, sufrida en Cuba con particular intensidad, no era precisamente el mejor aval para aventuras de este tipo. De ahí, las prevenciones.

De hecho, transcurridos pocos meses, su actividad prácticamente se redujo a la mera negociación de efectos públicos, tal y como sucede en la mayoría de las Bolsas emergentes del siglo $\mathrm{XIX}^{13}$. La vida de la Bolsa no se prolongó más allá de 1867, presumiblemente a causa de la crisis de 1866 y del estallido de la guerra de los Diez Años. Desde entonces, los especuladores practicaron la compraventa de activos financieros en plena calle, junto a la plaza de Armas, sin más respaldo oficial que el que brindaba el Colegio de Corredores, que anotaba y comunicaba a la Administración metropolitana las transacciones.

\footnotetext{
11 Betancourt (1909, p. 49); Archivo Histórico Nacional (AHN), Ultramar, leg. 48, exp. 4.

12 Vilar (1990, pp. 115-117).

13 Cazé (1861, pp. 348-442).
} 


\section{GRÁFICO 3}

EXPORTACIONES DE AZÚCAR A ESTADOS UNIDOS Y COTIZACIONES DE LA BOLSA DE LA HABANA, 1910-1959 (EN NÚMEROS ÍNDICES BASE $1950 \mathrm{Y}$ TÉRMINOS REALES)

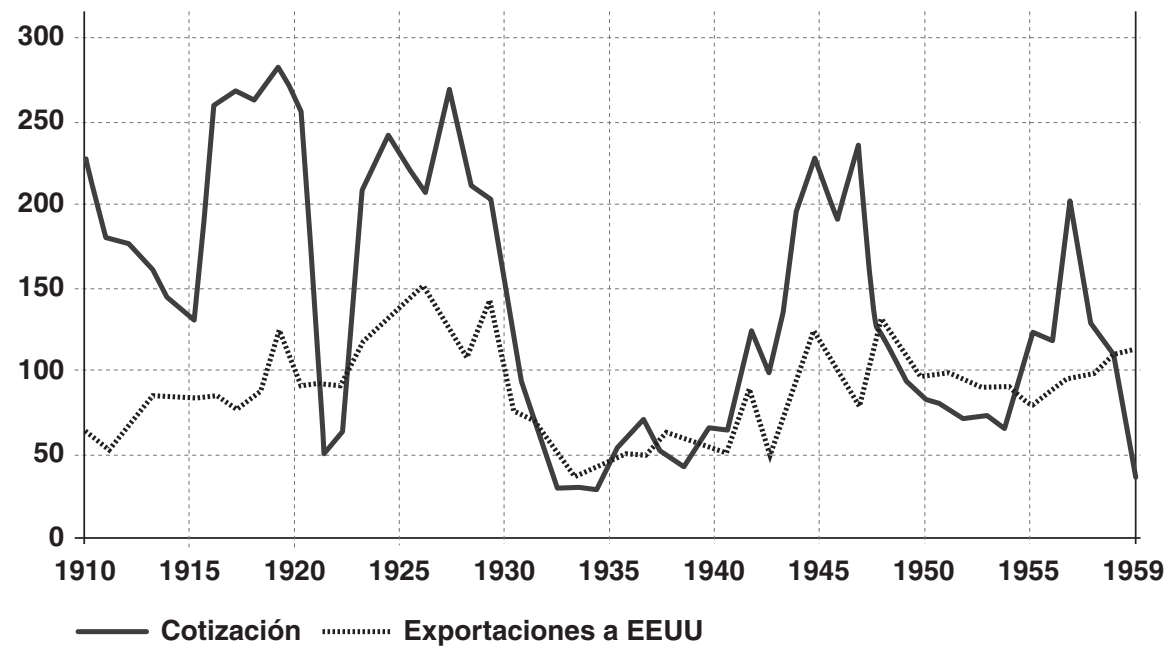

Fuente: ANC, Bolsa de La Habana, Actas de Cotización y Anuario Azucarero (1958).

Concluida la guerra, el mercado informal de acciones, obligaciones y títulos de deuda ganó en vigor. Sin embargo, en 1878 el Ejecutivo desestimó la petición de Plácido Castroverde y Pedro Codina de organizar una nueva Bolsa de Comercio ${ }^{14}$. En su ausencia, se produjeron «repetidas irregularidades» y escándalos que llevaron al propio capitán general a hacer suya esta reivindicación, atendida por fin en $1882^{15}$. La Bolsa quedó habilitada en un caserón de la calle Mercaderes prestado por el comerciante Francisco Jover, donde se negociaron un total de 19 títulos. Justamente la propiedad privada de su domicilio suscitó las suspicacias de las autoridades, quienes suspendieron sus sesiones dos años más tarde. Los corredores de comercio, pues, volvieron a formalizar sus transacciones a la intemperie.

Después de este segundo traspiés, el 28 de enero de 1886 la Gaceta de Madrid publicó los requerimientos oportunos para el establecimiento de Bolsas de Comercio en la isla de Cuba sobre bases más sólidas. Tras los preceptivos (y demorados) pronunciamientos del Consejo de Estado, se

\footnotetext{
14 AHN, leg. 153, exp. 12.

15 Biblioteca Nacional José Martí, Colección ficticia Vidal Morales, t. 63, nº 4 y Mia F. v. 173, $\mathrm{n}^{\circ} 32$.
} 
erigió en agosto de 1889 la de La Habana como ente de derecho público ${ }^{16}$. Es contemporánea, pues, a la de Ciudad de México y muy anterior a las fundadas en el resto de América Latina, con la excepción de la de Río de Janeiro en 1845, la de Buenos Aires en 1854, la de Lima en 1860, la de Montevideo en 1867 y la de Rosario en 1884.

Pero la sacarocracia habanera interpretó la decisión como una intrusión metropolitana, a la que respondió organizando en enero de 1894 la suya propia, bajo la denominación de «Bolsa Privada de La Habana», con el argumento de que «así lo exige la cultura, el movimiento y el adelanto de esta capital». En un primer momento, tuvo por sede los bajos de la Lonja de Comercio hasta que la entidad se hizo con sus propias dependencias en Obra Pía ${ }^{17}$.

Así pues, durante un tiempo coexistieron dos Bolsas: una auspiciada por los mandatarios coloniales y la otra nacida de la sociedad civil local. El divorcio entre ambas esferas de la vida pública habanera se llevó, pues, al plano financiero. La Bolsa privada acabó ganando la partida, una vez disuelta la pública por el Gobierno de la isla en abril de $1898^{18}$.

Creada por el impulso espontáneo de la burguesía capitalina sin tutela estatal, la Bolsa supo sobrevivir a la guerra (1895-1898) y continuar con sus operaciones sin ningún soporte legal tras la firma del Tratado de París. Como tantas otras instituciones económicas, cumplió con sus tareas en un limbo jurídico durante los primeros años del siglo XX, sin más fortaleza que la que proporcionaron la inercia y las buenas intenciones de sus promotores ${ }^{19}$.

Finalmente el Ejecutivo presidido por el liberal José Miguel Gómez en agosto de 1910 restableció la oficialidad de la Bolsa de La Habana, en la que pusieron en circulación sus acciones una veintena de compañías, en su mayor parte domiciliadas en la capital, regida por los estatutos de 1894 .

En ella concurrieron inicialmente 15 agentes de cambio y bolsa colegiados (el más potente de ellos, Emilio Larramedi, quien recibía órdenes de compra-venta de todo el país). En 1959, su número se elevó a 40. Los agentes, facultados avalados forzosamente por un socio de la Bolsa y habilitados para el ejercicio de sus funciones por la Junta Sindical, debían hacerse con un billete de a 10 centavos para ingresar en el edificio. No se practicaban operaciones más que al contado. Las de pago a plazo o las que excluían la percepción de dividendos el primer año quedaron relegadas a las transacciones over the counter, cada vez más extendidas desde 1922. En el calle Obispo, en torno al edificio de la Bolsa y de la sede del Banco Nacional de Cuba, se formó entonces el que se llamó "pequeño Wall Street habanero», transitado por corredores, agentes y logreros. Por eso, el empuje de la Bolsa oficial distó mucho del previsto.

\footnotetext{
16 Betancourt (1909, p. 49); AHN, Ultramar, leg. 281, exp. 9.

17 Bolsa Privada de La Habana (1894).

18 Pérez (1957, p. 48).

19 Bolsa Privada de La Habana (1906).
} 
La negociación de efectos públicos fue completamente residual (entre 1910 y 1922 nunca superó el 0,2\% de los valores contratados). Al margen de que Cuba financió su deuda, en gran parte, en el exterior, los títulos públicos resultaron mucho menos atractivos para los inversores que los privados, sobre todo en años de bonanza y buenas perspectivas en el mercado azucarero $^{20}$.

Precisamente, llama la atención la ausencia de empresas azucareras, cuyos propietarios, tal y como refería con anterioridad, prefirieron la bolsa neoyorquina. Esto obedeció, en parte, a su distinción institucional de la Lonja de Comercio (creada en 1878). En la Bolsa de La Habana no se practicaron transacciones con el azúcar similares a las de Buenos Aires, donde los mismos comerciantes intervenían en la compra-venta de acciones y en la contratación de granos en el mercado de futuros. Por el contrario, la Bolsa de Nueva York, el referente mundial en el mercado del azúcar, sí ofreció tal posibilidad. La habanera reinició su andadura lastrada por esa débil conexión con la principal actividad económica del país, por más que la pautase.

Los logros de la entidad en el inicio de su nueva andadura fueron más bien escasos. La Bolsa de La Habana movilizó en 1910 un capital de 24,5 millones de pesos, de los 100 que, en 1894, pretendían captar (con arreglo al capital nominal de las empresas cotizadas).

Adicionalmente, a comienzos de la década de 1910, a pesar del favorable comportamiento del precio del azúcar, la economía de la isla todavía no se había sacudido de las secuelas de la guerra, de los trastornos de la segunda ocupación norteamericana (1906-1909) y de la crisis financiera de 1907 (Gráficos 1 y 2). Los efectos del Tratado de Reciprocidad comercial acordado con Estados Unidos en 1902 no se habían dejado sentir aún en el mercado de capitales ${ }^{21}$. La comparación con lo sucedido en la Bolsa de Nueva York resulta, en este sentido, extraordinariamente reveladora (Gráfico 2): allí, la caída de las cotizaciones no fue tan brusca e intensa, salvo justamente la de los cubanos, como la vivida en La Habana.

\section{LA FEBRILIDAD BÉLICA, 1914-1918}

La economía y las finanzas de la Cuba independiente recibieron su primer gran impulso desde el exterior con el estallido de la guerra mundial, que redundó en un aumento de las exportaciones y en una mejora de su posición exterior desconocidos en esa magnitud hasta la fecha (Gráfico 4$)^{22}$.

A ello contribuyó la normalización monetaria del país. Así, en 1914, el Gobierno dispuso la acuñación por el Tesoro del peso como moneda nacional con idéntico gramaje que el dólar y la adopción del patrón oro.

20 Secretaría de Hacienda (1908-1921), pássim.

21 Zanetti (2003, pp. 72-75).

22 Véase Cuban investments (1916); Zanetti (2003, pp. 81-89). 


\section{GRÁFICO 4}

SALDO COMERCIAL Y COTIZACIÓN DE LA BOLSA DE LA HABANA, 1910-1957 (EN MILLONES DE PESOS CORRIENTES Y NÚMEROS ÍNDICES BASE 1950)

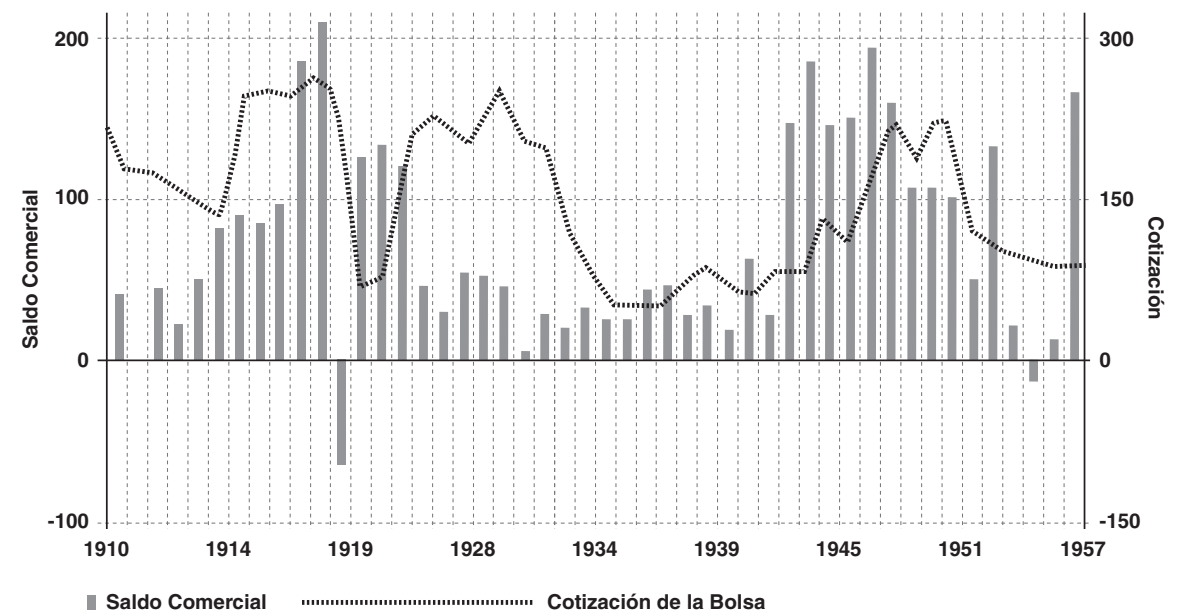

Fuente: ANC, Bolsa de La Habana, Actas de Cotización, Roselló (1954, p. 155) y Ministerio de Hacienda (1958, pp. 289-290).

La emisión de billete siguió en manos del Banco Español de la Isla de $\mathrm{Cuba}^{23}$.

Debido a las singularidades del sistema impositivo, heredado del período colonial, en el que todavía las rentas de aduanas tenían una importancia muy significativa en la conformación de los ingresos del Estado, la guerra mundial contribuyó al saneamiento de las cuentas de la República. El saldo presupuestario positivo constituyó un estímulo añadido a la apreciación de los títulos de renta variable, a causa de la disminución de las emisiones y de la reducción de deuda en circulación (Gráfico 5).

El superávit comercial obedeció al incremento de las ventas de azúcar en el exterior. Estados Unidos se reservó la compra del conjunto de la producción cubana, a fin de garantizar el abastecimiento interno, lo que, a despecho de las discusiones por el precio fijado, generó un enorme caudal de ingresos para las grandes corporaciones de la isla. De hecho, en 1916 ingresó en la Bolsa de Cuba la más potente de las empresas azucareras, la Cuban Cane Sugar Corporation, en la órbita del mencionado Manuel Rionda, convertida, con un capital de 50 millones de pesos, en la mayor de todas ellas $^{24}$. Por fin, el sector se involucró con el acontecer bursátil habanero.

23 Pérez y Pazos (1940); Roldán (2005).

24 McVoy (2003). También lo hizo en ese año la más modesta Ciego de Ávila Compañía Azucarera (1.200.000 pesos). 


\section{GRÁFICO 5}

SALDO DE LAS CUENTAS DEL ESTADO Y COTIZACIONES DE LA BOLSA DE LA HABANA, 1910-1950 (EN MILLONES DE PESOS CORRIENTES Y NÚMEROS ÍNDICES BASE 1950)

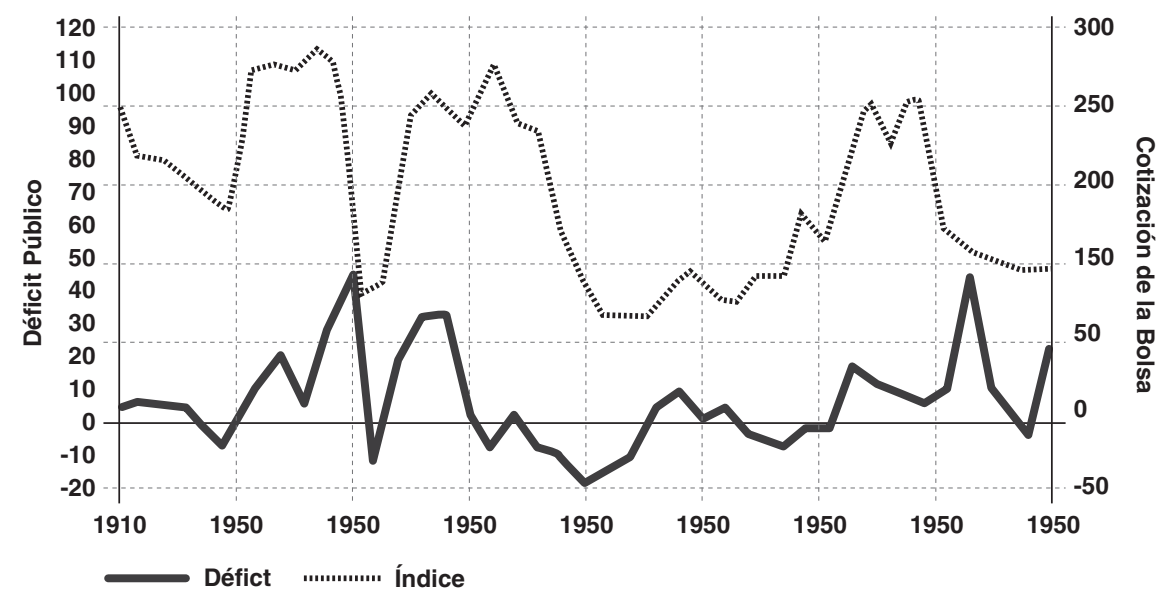

Fuente: ANC, Bolsa de La Habana, Actas de Cotización, Roselló (1954, p. 155).

Sin embargo, estas compañías se financiaron, sobre todo, mediante el crédito y la emisión de obligaciones, suscritas por entidades bancarias, amortizables en ambos casos en el muy corto plazo y con tipos de interés pautados por el precio esperado del azúcar. Dado que las dos únicas entidades financieras dignas de tal nombre, El Banco Español y el Banco Nacional, literalmente no daban abasto, las necesidades de crédito fueron satisfechas por otros intermediarios: El Banco Gómez Mena, el Banco Mercantil, el Banco Internacional, el Canadian Bank of Commerce y el American Foreign Bank Co., entre otros ${ }^{25}$. Comerciantes de toda ralea y no siempre de gran fortuna abrieron decenas de casas de banca con mera proyección local cuya única misión era captar fondos para prestarlos a un tipo de interés leonino a colonos y propietarios de centrales ${ }^{26}$. El número de bancos establecidos en Cuba pasó de 26 en 1912 a 394 en 1920 y 39 en $1932^{27}$.

El incremento de la retribución y de las exportaciones de azúcar estimuló una notable apreciación de los valores en Bolsa. La Naviera Cubana supo sacar provecho de esta intensificación del tráfico (Gráfico 6). También la demanda estadounidense repercutió en la consideración por parte de los especuladores de otras empresas proveedoras de alimentos, y en particular, de las de las cerveceras y de las industrias de la refrigeración. Más moderada fue la mejora

\footnotetext{
${ }^{25}$ Roselló (1954, p. 921).

26 Wolter (1937, p. 101); Dye (1994).

27 Ricardi (1954, pp. 32-35).
} 


\section{GRÁFICO 6}

COTIZACIÓN DE DIVERSOS VALORES EN LA BOLSA DE LA HABANA, 1911-1959

(EN NÚMEROS ÍNDICES BASE 1950)

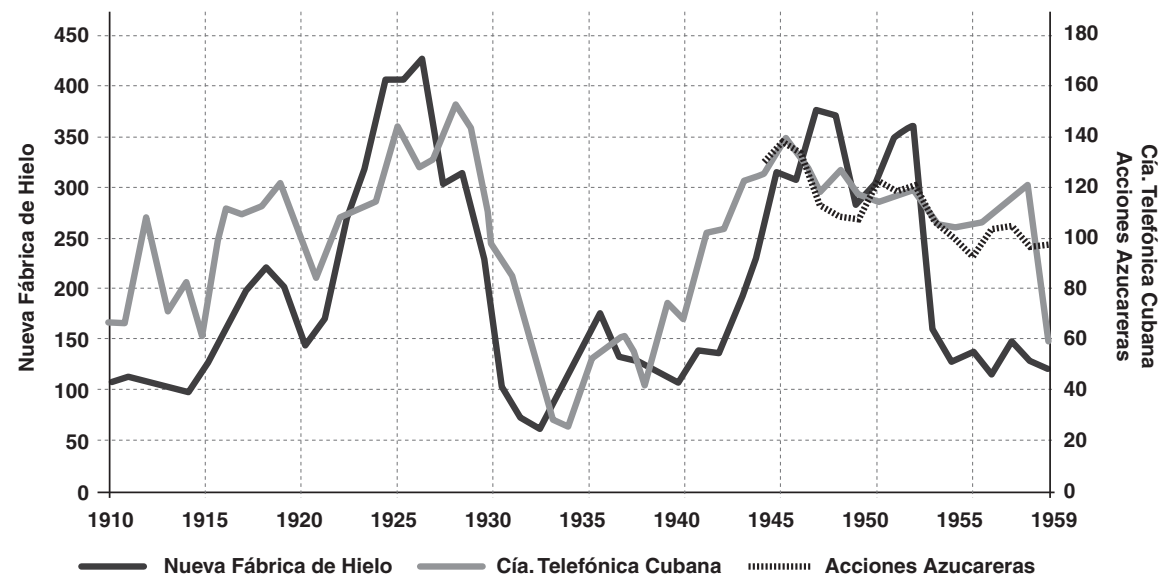

Fuente: ANC, Bolsa de La Habana, Actas de Cotización.

de las cotizaciones de la Compañía Telefónica Cubana. Otro tanto puede decirse de las de las compañías ferroviarias, tradicionalmente sujetas a la competencia de las líneas pertenecientes a los centrales, a unos mayores costes financieros y a la carga que representaba la amortización de sus activos.

Un auténtico fervor bursátil se desató en estos años. Medio centenar de empresas cubanas creyó encontrar en la Bolsa el instrumento de financiación del que carecían, todo un logro. Firmas petrolíferas (Union Oil Co.), mineras (Constancia Copper Co.), alimenticias (Cuba Industrial y Comercial), roneras (Licorera Cubana), manufactureras (Compañía Internacional de Calzado y Compañía de Jarcias de Matanzas), de seguros (hasta media docena de ellas), pesqueras (Compañía Cubana de Pesca) o la mencionada Naviera Cubana se unieron a la institución en pleno ardor especulativo, entre 1916 y 1918. Incluso el banco Hispanoamericano español lo hizo en 1917.

Pero fue el Banco Nacional de Cuba el mayor beneficiario de esta coyuntura tan excepcional, pasando de una cotización de 120 pesos corrientes en 1915 a 180 en 1918 y 1919. No en balde, la casa matriz, The Trust Co., cotizó también en La Habana desde 1916.

\section{5. «LA DANZA DE MILLONES»Y EL PÁNICO FINANCIERO (1919-1925)}

La declaración del armisticio no causó mayor alarma entre los inversores cubanos, en tanto que, con arreglo a sus predicciones, la producción europea de remolacha tardaría años en remontar. En 1919, el índice de la Bolsa 
alcanzó su máximo histórico. De hecho, la zafra creció ese año un $22 \%$. Suprimidos los controles por el Gobierno de Estados Unidos, el precio del azúcar se duplicó. La Bolsa seguía siendo germen de fabulosos negocios en esos años de la llamada "Danza de Millones» ${ }^{28}$. El más atractivo de todos ellos, el inmobiliario, inducido por las faraónicas obras en El Vedado habanero y en los repartos de La Lisa y Miramar promovidas por Mario García Menocal, presidente entre 1913 y 1921, alentó la creación de un buen número de empresas constructoras, muchas de ellas cotizadas.

Sin embargo, esta euforia bursátil no tardó en irse al traste ${ }^{29}$. En el verano de 1920, el precio del azúcar se desplomó tras estallar la burbuja especulativa inducida por la liberalización del mercado del azúcar ${ }^{30}$. Los mayoristas se encontraron entonces con enormes stocks de este producto ahora depreciado, cuya compra había consumido gran parte de su fortuna. Habida cuenta de la caída de sus ingresos, los titulares de centrales no estaban en condiciones de amortizar las obligaciones emitidas, lo que situó al borde de la quiebra a los bancos, los principales suscriptores y tenedores de estos títulos. El pánico se desató entre la población de La Habana, que, en los primeros días del mes de octubre, procedió a retirar sus depósitos cuando fue posible, ya que los grandes bancos británicos, canadienses y estadounidense habían repatriado antes buena parte de sus pasivos ${ }^{31}$. El día 4 de ese mismo mes, el Gobierno dictó un "corralito», que impidió la disponibilidad de más del 10\% de los depósitos de los impositores, siempre que su montante fuese inferior a los 10.000 pesos.

Por otra parte, la caída del precio del azúcar exportado provocó un déficit comercial, circunstancia desconocida desde los primeros años de vida de la República y letal para una economía tan abierta. Esto se tradujo en un inevitable aumento del déficit público, debido al descenso en la recaudación que causó la atonía, y en el consiguiente aumento de la deuda en circulación (Gráficos 4 y 5). Así las cosas, la cotización de las acciones en Bolsa disminuyó drásticamente (Gráfico 2) ${ }^{32}$. Como no podía ser de otra manera, los inversores huyeron apresuradamente del parqué. El volumen negociado pasó de casi 3,4 millones de pesos en 1919 a 2 millones en 1920, y luego cayó a 45.000 pesos corrientes en 1921, un 1,3\% del alcanzado en 1919 . Los inversores buscaron refugio en la deuda pública, cuyo volumen en circulación aumentó para cubrir la falta de ingresos aduaneros, y su cotización se mantuvo más firme ${ }^{33}$.

La Administración cubana, maniatada por el dirigismo estadounidense, cuyos emisarios dictaban medidas de política económica que Menocal

\footnotetext{
28 Le Reverend (1975, pp. 176-179).

29 Véase Santamaría (1994).

30 Dye (1998).

31 Le Reverend (1975, pp. 176-179).

32 Sobre la crisis financiera véase Mascarós (2003) y Collazo (1994).

3 Secretaria de Hacienda (1918-1921), pássim.
} 
acataba sin rechistar, carecía de instrumentos y espacio de maniobra para atajar la crisis. Ni siquiera existía en el país un banco central. Fue imposible articular una política monetaria que contuviese la debacle. El Gobierno no tuvo otro remedio que trasmitir al presidente de la Bolsa, Pedro Pablo Kohly y O'Reailly, el 18 de octubre, su clausura sine die "por motivo de la crisis bancaria». La resolución no causó mayores traumas para las grandes empresas azucareras, que siguieron cotizando en Nueva York, donde no hubo tanto sobresalto (Gráfico 2). El miedo y la zozobra eran cosa de las finanzas liliputienses habaneras, que Rionda y sus colegas miraban de soslayo.

La crisis castigó con dureza implacable a todas las grandes firmas cotizadas (Gráfico 6). En el caso de las roneras, los efectos de la Ley Seca aprobada por Estados Unidos en 1919 agravaron todavía más las dificultades. Pero la situación afectó sobre todo a las entidades financieras. Tanto el Banco Español de la Isla de Cuba como el Banco Nacional de Cuba fueron liquidados, en este último caso tras el suicidio de su principal accionista, el gallego José López Rodríguez, alias Pote, propietario de varios centrales y promotor de la urbanización del reparto de Miramar $^{34}$. Desde entonces el, de suyo, débil sistema bancario vernáculo estuvo representado exclusivamente por el Banco Territorial de Cuba.

En la primavera de 1921, se reanudaron las transacciones en la Bolsa de La Habana; sin embargo, la atonía en la negociación de valores durante ese año y en 1922 fue absoluta. En realidad, los agentes se reunían a diario en el edificio de la Bolsa para compartir sus amarguras, sin realizar apenas transacciones.

Los inversores, con todo, no tardaron en olvidar lo sucedido. En 1923 igualó las cotizaciones prebélicas (Gráfico 2). Todavía era factible hacer dinero en la Bolsa, concebida, cada vez más, no como un instrumento de financiación (labor que cumplía ejemplarmente la de Nueva York), sino de especulación al alza o a la baja en el corto plazo.

De hecho, esta renovada febrilidad bursátil no era congruente con la posición exterior de la economía cubana (Gráfico 3), en tanto que las exportaciones de azúcar seguían bajo mínimos debido al aumento de los derechos que devengaba su importación en Estados Unidos en 1921 y $1922^{35}$. Desde luego, el aumento de la demanda de los valores industriales no procedió de una menor negociación de títulos públicos, dado que se produjo un déficit puntual en 1921, y después las cuentas del Estado se mantuvieron con saldo positivo hasta 1925. Subía la Bolsa cuando bajaba el precio del azúcar y aumentaba la deuda en circulación, lo que aparentemente carecía de toda lógica. El cotejo de la evolución de la renta disponible con el de la cotización bursátil parece sugerir un aumento del ahorro que afluyó a inversión en

\footnotetext{
34 Le Reverend (1975, pp. 162-164).

35 Dye (2005, p. 204). Véase, sobre este período, Zanetti (2003, pp. 90-104).
} 


\section{GRÁFICO 7}

RENTA PER CÁPITA Y COTIZACIÓN DE LA BOLSA DE LA HABANA, 1910-1959 (EN PESOS CORRIENTES Y NÚMEROS ÍNDICES BASE 1950)

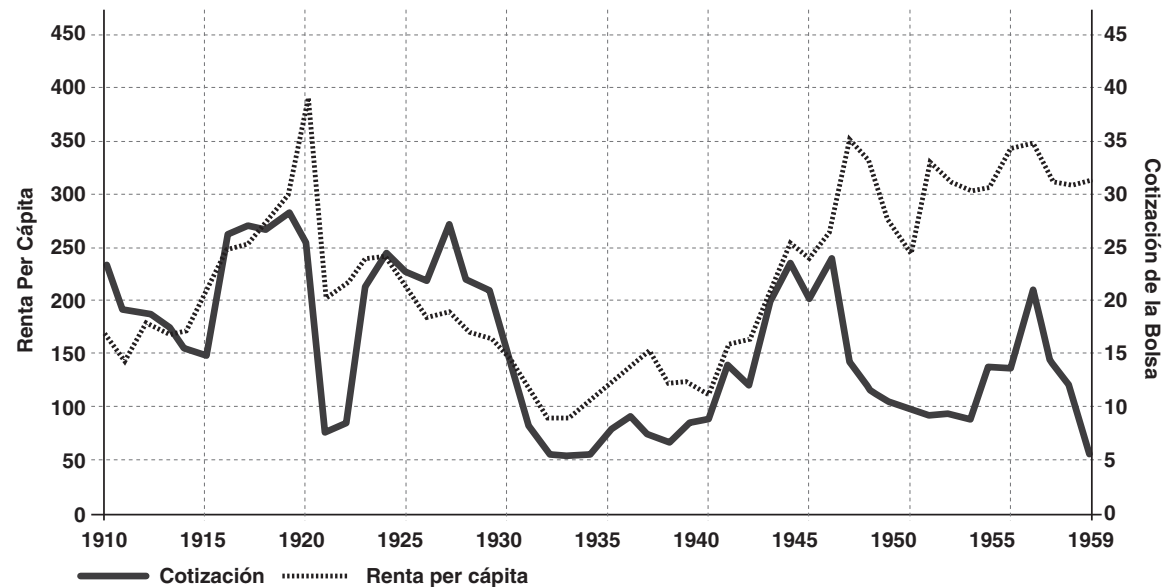

Fuente: Alienes (1949, p. 52), Banco Nacional de Cuba (1951-1959) y ANC, Bolsa de La Habana, Actas de Cotización.

valores (Gráfico 7) ${ }^{36}$. Los corredores operaban con la expectativa de una apreciación del azúcar en el corto plazo y de la distribución de elevados dividendos por las empresas urbanizadoras. Tal fue la causa de este dislate. En suma, se creó una nueva burbuja financiera que acabaría por estallar unos años después.

\section{LA CRISIS DE 1929: PROLEGÓMENOS, MANIFESTACIONES Y CONSECUENCIAS (1926-1939)}

A lo largo de 1926, cuando Cuba sufrió el contagio de la crisis mexicana, el país padeció, de nuevo, los dañinos efectos de los vaivenes en el mercado mundial del azúcar (Gráficos 1 y 3). Su inopinada depreciación en Estados Unidos ocasionó una nueva minoración del índice bursátil, azuzada en esta ocasión por el incremento del déficit público y la competencia de los valores emitidos por el Gobierno (Gráfico 5). La mayor intervención estatal a que estuvo sujeto el sector azucarero desde entonces acrecentó la desconfianza de los inversores, trasmitida incluso al mercado neoyorquino (Gráfico 2$)^{37}$.

36 Santamaría (2000) ha reconstruido de manera muy convincente en PNB cubano en el período. Sin embargo, yo me he inclinado por las macromagnitudes estimadas por Alienes debido a su mayor adecuación a los objetivos analíticos de este trabajo y a los agregados que aquí se presentan.

37 Zanetti (2003, pp. 104-105). 
Aunque la caída de las cotizaciones en la Bolsa no fue tan acentuada como la experimentada a comienzos de la década ni sus repercusiones en el raquítico sistema financiero tan graves, el declive de 1926-1928 tuvo consecuencias en el plano empresarial nada desdeñables. La Cuban Tire and Rubber Co., la Compañía Internacional de Calzado, la Ciego de Ávila Compañía Azucarera, la Unión Hispanoamericana de Seguros y la Unión General de Seguros y Accidentes abandonaron el parqué, envueltas, algunas de estas firmas, en procedimientos concursales. El cambio de coyuntura malogró también la ejecución de los megalómanos proyectos urbanísticos diseñados en los años de la primera guerra mundial que sobrevivieron a la hecatombe de 1920, como el proyectado por la Compañía Urbanizadora del Parque y Playa de Marianao, o grandes obras públicas, caso del acueducto de Cienfuegos. La AT\&T se desligó de la Bolsa de La Habana en 1928, tan solo tres años después de su desembarco en ella. En ese ejercicio, solo cotizaban 28 compañías, la mitad de las que lo hacían diez años atrás.

Así pues, la crisis de 1929 no sorprendió del todo a los actores económicos cubanos $^{38}$. A pesar de que el martes 29 de octubre, cuando se divulgó lo sucedido en Nueva York el «jueves negro», la cotización del Banco Territorial de Cuba y de las compañías ferroviarias se desplomó, a lo largo de esa semana hubo cierta calma en la Bolsa habanera. Pero el pavor se adueñó de los inversores pocos días más tarde, hasta el punto de que los índices de La Habana se pueden equiparar con los de la Bolsa neoyorquina (Gráfico 2).

La recesión iniciada entonces fue mucho más profunda y dilatada que la sufrida en 1920. El precio del azúcar se hundió entre 1929 y 1932, al igual que las exportaciones, a consecuencia de las medidas proteccionistas dictadas por Estados Unidos y los países europeos ${ }^{39}$. Las acciones de la Cuban Cane Sugar Corporation se depreciaron hasta el punto de que su precio en 1930 representaba una centésima parte del nominal, poco más del valor del papel en el que estaban estampadas ${ }^{40}$. Los valores cubanos, incluida la deuda externa, perdieron su acreditación entre los inversores estadounidenses, que desconfiaban de la resolución y el liderazgo de los mandatarios cubanos (Gráfico 2).

Los oligarcas isleños retiraron masivamente sus depósitos en la banca nacional para buscar refugio en Estados Unidos (pasaron de 222 millones de pesos en 1929 a 88 millones en 1933), comenzando así una fuga de capitales continua hasta $1959^{41}$.

Cuba, por su estrecha relación con la economía estadounidense, sufrió la depresión de manera mucho más honda y prolongada que ningún otro país

38 Véase Marichal (2010, pp. 85-135).

39 Véase Zanetti y García (1987, pp. 311-334).

40 Véase McAvoy (2003, pp. 154-158).

41 Roselló (1954, p. 921); Maddison (1985, p. 36); Truslow (1951, p. 524); Pérez y Pazos (1940, p. 29). 
de América. La comparación con los registros bursátiles chilenos resulta muy esclarecedora a este respecto ${ }^{42}$. El problema radicaba en que, debido a la ausencia de soberanía financiera, el Gobierno cubano no podía devaluar el peso, amordazado por la continuidad de su convertibilidad en oro, instrumento imprescindible para atenuar el déficit comercial y corregir el desajuste de las cuentas públicas. El Gobierno de Washington, perseverante e implacable en la defensa de las inversiones estadounidenses, con todo, jamás lo habría permitido ${ }^{43}$.

Las lisonjeras perspectivas que despertaron los tratados internacionales signados desde 1931 para contener la sobreproducción y formar un gran trust azucarero a escala mundial hicieron que las cosas mejorasen tímidamente en 1932, sobre todo en lo que concernió a las obligaciones, en atención a prioridad de pago en los procedimientos de quiebra (Gráfico 1$)^{44}$. Pero bastó un año para desbaratar esas convicciones. El sistema de preferencias imperiales acordado en Ottawa relegó al azúcar cubano en el tan disputado mercado británico. Cuba se enzarzó en una perversa guerra de precios con Java ${ }^{45}$. A lo largo de 1933, la caída de los ingresos salariales y el aumento del paro ocasionaron violentas tensiones sociales. Los planes de obras públicas aprobados por Machado no pudieron poner coto al descontento ${ }^{46}$. El levantamiento popular del 4 de septiembre fue recibido en la Bolsa con alarma y la tradicional huida de capitales, cuya magnitud sorprendió incluso a los observadores extranjeros ${ }^{47}$.

La firma del convenio comercial con Estados Unidos y la Ley CostiganJones de 1934 empeoraron la situación, en tanto que penalizaron fiscalmente las exportaciones de azúcar, sometidas desde ese año a un férreo sistema de cuotas $^{48}$. Al tiempo el tratado contempló la reducción de los aranceles que devengaba la importación de Estados Unidos, lo que dañó a industrias como la zapatera, por citar un caso representado en la Bolsa, malbaratando así los escasos logros de las reformas nacionalistas y proteccionistas de Machado de $1927^{49}$; el consumo de energía eléctrica y de cemento, un buen indicador del nivel de actividad, así lo corrobora (Gráfico 8).

La economía cubana y, con ella, la Bolsa experimentaron un pequeño respiro en 1938, al amparo de una tímida subida del precio del azúcar en Estados Unidos y de la nacionalización de las empresas petroleras mexicanas por el presidente Lázaro Cárdenas en marzo de ese año, convencidos los agentes habaneros de que los inversores estadounidenses iban a prestar una mayor atención a su país; pero resultó un espejismo (Gráficos 1 y 2).

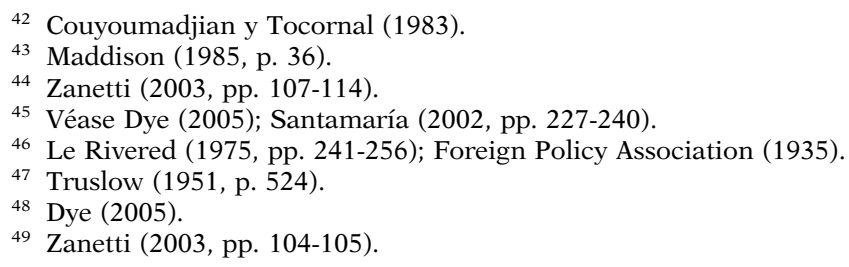




\section{GRÁFICO 8}

COTIZACIONES DE LA BOLSA DE LA HABANA Y CONSUMO PÉR CAPITA DE CEMENTO Y DE ELECTRICIDAD, 1910-1959 (EN NÚMEROS ÍNDICES BASE 1950)

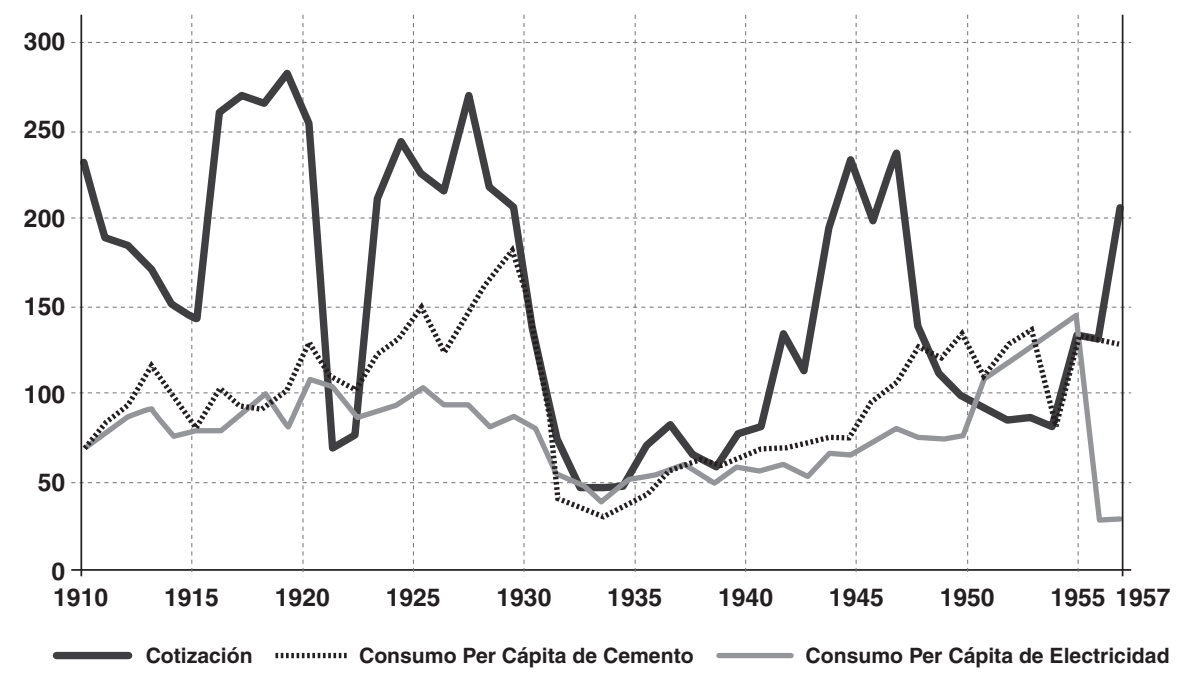

Fuente: ANC, Bolsa de La Habana, Actas de Cotización y Ministerio de Hacienda (1958).

No obstante, lo sucedido en México y las revueltas de 1933 obligaron al Gobierno de Estados Unidos a reflexionar sobre la naturaleza de sus relaciones financieras y comerciales con Cuba por temor a ver aquí también lesionados sus intereses. El Departamento del Tesoro formó a instancias propias la Comisión Técnica de Legislación Bancaria y Monetaria, con el fin de estudiar la creación de un banco central, como se había hecho en 1935 en Argentina y otros países latinoamericanos ${ }^{50}$. Pero el altruismo estadounidense tenía un límite: la idea cayó pronto en el olvido ${ }^{51}$.

La recesión comportó el completo desapego de la economía cubana de la Bolsa, una anécdota en el minúsculo mercado de capitales de la isla. A finales de la década de 1930 apenas cotizaban dos docenas de compañías, ninguna de ellas azucarera, tabaquera o cafetalera. No era preciso: Ya lo hacían en la de Nueva York. El gran capital cubano buscó refugió en Estados Unidos y, con él, sus valores industriales más acreditados. De ahí la marcha dispar de la renta disponible (y por consiguiente, del ahorro) y la cotización de las acciones experimentada en Cuba desde entonces (Gráfico 7).

50 La Bolsa de Comercio de Buenos Aires (1954, p. 57); Meisel (2008).

51 Ricardi (1954, p. 32). 


\section{LA GUERRA EDULCORANTE Y LA NUEVA BURBUJA FINANCIERA (1940-1951)}

La entrada de Estados Unidos en la segunda guerra mundial hizo olvidar la pretensión consagrada en la Constitución de 1940 de emprender una senda alternativa de desarrollo, una vez demostrada la inviabilidad de la seguida hasta la fecha.

Cuba cayó otra vez en el sueño letárgico del azúcar ${ }^{52}$. Las oligarquías, lejos de aventurar sus recursos en inversiones alternativas, se sumieron en el empeño de enriquecerse con lo que les obsequiaba el conflicto, abasteciendo de este bien a los Estados Unidos y aun a Alemania, mediante reexportaciones desde España ${ }^{53}$. Otro tanto sucedió con el café y el tabaco. De nuevo, Cuba y sus empresarios sucumbieron a la quimera financiera, a la seducción del dinero fácil, a la tentación de maximizar la rentabilidad en el muy corto plazo. Una vez más, el mundo de las finanzas y el de la economía real recorrieron caminos separados, lo que en la isla se había convertido ya casi en un dogma.

En esta ocasión, los empresarios eludieron en lo posible el endeudamiento bancario, fuese mediante la emisión de obligaciones o la contratación de préstamos de avío, para evitar sobresaltos como los vividos en 1920. Por su parte, los bancos se mostraron mucho más reacios al crédito, al punto de que el encaje bancario aumentó en estos años ${ }^{54}$.

En tales circunstancias, los grandes empresarios repararon en las posibilidades de una, entonces, periclitada Bolsa. El número de firmas cotizadas pasó de 16 en 1939 a 46 en 1947; una docena de ellas, azucareras, entre las que ya se encontraba la estadounidense United Fruit Co. ${ }^{55}$

El juego de la Bolsa procuró ingresos extraordinarios a quienes negociaron con los títulos de las empresas más favorecidas por la coyuntura bélica: las productoras de alimentos y bebidas para suministro de las tropas estadounidenses (Gráfico 6), las navieras y, en menor medida, las ferroviarias. Por dar alguna referencia añadida, la demanda exterior situó a la fábrica de la Compañía de Jarcias de Matanzas entre las mayores transformadoras del mundo de henequén. Todavía más esclarecedoras de la excepcionalidad de la situación resultan las exportaciones de ron, multiplicadas a lo largo de 1942 por ¡27! En total, la guerra generó un ahorro añadido de 105 millones de pesos, equivalentes a un $23,4 \%$ del PIB de $1940^{56}$.

Concluida la guerra, las cotizaciones bursátiles siguieron al alza, gracias a la persistencia de la carestía del azúcar y a la aprobación del llamado «diferencial azucarero», un programa de obras públicas financiado con los

\footnotetext{
52 Zanetti (2003, pp. 133-141).

53 Le Revered (1975), pássim; Zanetti (2009, pp. 154-192).

54 Alienes (1949, p. 169).

55 Zanetti y García (1976).

56 Alienes (1949, p. 169) y (1950, p. 52).
} 
rendimientos obtenidos de la venta del producto de la caña. El texto incluyó también una mejora de los salarios reales que, es ocioso decir, quedó en poca cosa. Al amparo de este alambicado y desmesurado plan de inversiones en infraestructuras (en realidad, todas ellas de ocio y todas ellas en La Habana) entraron en la Bolsa empresas como la Compañía Operadora de Stadiums, propietaria del estadio de pelota de El Cerro, o la Concretera Nacional, ambas en $1947^{57}$. Pero, sobre todo, la Bolsa dio la bienvenida con gran alborozo a las dos firmas aéreas nacionales, en plena resaca bélica: la Compañía Cubana de Aviación, empresa mixta de la que era accionista mayoritario el mismísimo Fulgencio Batista, y Expreso Aéreo Interamericano ${ }^{58}$.

Incluso el volumen de comercio exterior aumentó merced a la multiplicación de operaciones de intercambio con otros países del entorno sin mediar pago en divisas mediante el comercio de contingentes ${ }^{59}$.

Pero, una vez más, el crecimiento de las cotizaciones careció de sustento real (Gráficos 1, 2, 7 y 8). No hubo un incremento de la producción industrial (atendiendo al consumo de energía como indicador) de magnitud tal que justificase el ímpetu inversor en la Bolsa.

Como no podía ser de otra manera, y con bases tan frágiles, en diciembre de 1947 sufrió un nuevo crack (Gráficos 1, 2 y 6), debido a los drásticos cambios en el mercado mundial del azúcar que vislumbraron acertadamente los empresarios cubanos. Tras la aprobación del Plan Marshall en ese año, intervinieron con la certeza de una rápida recuperación de la producción de remolacha en Europa, en detrimento de las exportaciones nacionales. Pero, sobre todo, obraron guiados por el contenido de la Carta de La Habana, preludio del Acuerdo General de Aranceles de Comercio (GATT), signada en noviembre de 1947, que supuso una sentencia de muerte para la industria azucarera cubana ${ }^{60}$. Sólo las obligaciones emitidas por las empresas cubanas resistieron el declive (Gráfico 1).

En efecto, la "cláusula de nación más favorecida» desactivó las ya timoratas concesiones arancelarias norteamericanas, en tanto que deberían hacerse extensivas a otros países, con los que los Estados Unidos estaban ahora muy interesados en mejorar sus relaciones comerciales y diplomáticas: Brasil y la República Dominicana. De hecho, en 1948 redujeron la cuota importadora de azúcar asignada a Cuba, a consecuencia también del aumento de la producción de caña en Hawái y Puerto Rico ${ }^{61}$.

El desarrollo ulterior del acuerdo de La Habana permitió la entrada en los mercados de otros países, particularmente en los del Reino Unido, aunque en cantidades inferiores a las perdidas en Estados Unidos ${ }^{62}$. Mas el GATT dio

\footnotetext{
57 Jiménez (2008, p. 475).

58 Jiménez (2008, p. 239).

59 Le Reverend (1974, p. 645).

60 Ministerio de Estado (1947); Zanetti (2003, pp. 152-153).

61 Dye y Sicotte $(2004$, p. 680).

62 Zuaznábar (1986, pp. 35-36).
} 
sólo una libertad teórica de comercio a Cuba, ya que Washington vio desde el primer momento con muy malos ojos las ventas a la Europa del este, finalmente prohibidas en 1955.

La creación en 1948 (aunque solo efectiva en 1950) del Banco Nacional de Cuba, postergada una y otra vez desde 1922, recrudeció el declive bursátil $^{63}$. Las finanzas ahora debían someterse a la regulación y supervisión de la autoridad monetaria, poniendo fin a decenios de libérrima actuación de los agentes económicos, afectados por la prohibición de la circulación del dólar (aunque nunca del todo respetada) y por la competencia del Banco en las transacciones con deuda pública, de resultas de la implementación de las operaciones de mercado abierto. Los bancos no solo tenían que asumir tipo de descuento y coeficientes de caja obligatorios, sino competir con el propio Banco Nacional de Cuba en el crédito a corto plazo a las empresas azucareras.

En suma, la Bolsa de La Habana, que venía desarrollando sus actividades en un país donde regía la ley de la selva financiera, sin la menor regulación sobre la gestión y conformación de pasivos bancarios, y sin control alguno del crédito, tuvo que digerir un cambio de 180 grados en su mercado de capitales para homologarse con el propio de una economía capitalista avanzada ${ }^{64}$. La digestión fue lenta y pesada.

El declive azucarero precipitó a Cuba hacia una nueva recesión, con trágicos efectos en su nivel de renta (Gráfico 7). La coyuntura inquietó a los poderes públicos, por sus consecuencias en el nivel de empleo y el temor a que ocasionase nuevos levantamientos populares como los vividos en 1933. La Asociación Nacional de Industriales se apresuró a convocar la denominada Conferencia para el Progreso de la Economía Nacional ${ }^{65}$. Del encuentro se esperaba un recetario concreto de reformas estructurales que emulasen el crecimiento por sustitución de importaciones adoptado en el resto de América Latina (tal era su objetivo). Pero las propuestas fueron tan vagas e imprecisas como las del dichoso informe Truslow (1951), redactado con idénticas pretensiones y en el mismo contexto económico agónico al que tanto crédito dieron los gobernantes del país.

Nada influyeron, por tanto, este y otros foros en las negras expectativas empresariales. El contagio, en 1949, del crack de la Bolsa de Buenos Aires sumió a la habanera en la postración más absoluta ${ }^{66}$. En pleno marasmo, la venta de acciones para obtener liquidez solo pudo hacerse con una "cuantiosa pérdida en las cotizaciones», debido a la contracción de la demanda de títulos ${ }^{67}$.

\footnotetext{
63 Mascarós (2003).

${ }^{64}$ Véase Wolter (1938, pp. 100-101).

${ }^{65}$ Zanetti (2003, p. 150).

${ }^{6}$ La Bolsa de Comercio de Buenos Aires (1954, pp. 249-248).

67 Alienes (1950, p. 155).
} 
Para colmo de males, aumentó el tipo de interés, «absurdo por lo crecido», desincentivando la inversión ${ }^{68}$. A no dudarlo, en algunas zonas rurales del entorno de Holguín llegó a pagarse al 300\% ${ }^{69}$.

Cuba había desaprovechado la oportunidad industrializadora que posibilitó la guerra a causa, en buena medida, de su escaso desarrollo financiero ${ }^{70}$. La caída tendencial de los valores industriales alejó más a los inversores del parqué ${ }^{71}$. En su lugar, los beneficiarios de este nuevo baile de millones prefirieron emplearlos en la compra de bienes raíces en Miami o depositarlos en bancos extranjeros ${ }^{72}$.

El inicio de la guerra de Corea, en el verano de 1950, supuso algún alivio porque indujo un consabido aumento de las exportaciones (Gráficos 3$)^{73}$. Ahora bien, la contienda tuvo una repercusión menor en el mercado azucarero. Estados Unidos no concedió a Cuba el trato preferencial de otras ocasiones. Poco cambió, pues, en la Bolsa, estando los inversores aturdidos ante el nuevo escenario financiero nacido de la creación del Banco Nacional de Cuba.

\section{LA BOLSA, EL BATISTATO Y LA REVOLUCIÓN, 1952-1959}

Cuando el 10 de marzo de 1952 Fulgencio Batista llegó a la presidencia de la República por segunda vez, en esta ocasión tras perpetrar un golpe de Estado, la economía cubana y, por ende, sus finanzas, se encontraban en un estado de total abatimiento.

Para colmo de males, la zafra de ese año fue la mayor del siglo, sin posibilidad alguna de colocarla toda en el mercado estadounidense, lo que obligó al Gobierno a restringir la producción durante cuatro años a fin de acabar con los excedentes.

En 1953, ya concluida la guerra de Corea, Cuba perdió 250.000 t en su cuota de exportación tras la firma en Londres del Convenio Azucarero, lo que ahondó un declive que no dejó de reflejarse en el parqué (Gráficos 1 y 2). Incluso Standard and Poor's previno a los inversores sobre los riesgos de invertir en valores de la Bolsa habanera ${ }^{74}$.

Batista arbitró entonces los llamados "gastos compensatorios» incluidos en los retóricos Planes de Desarrollo Económico y Social, de pretendida

68 Alienes (1950, p. 152).

69 Mascarós (2003, p. 95).

70 Alienes (1949, p. 171) puso, de nuevo, el dedo en la llaga: «Como no se hizo lo que en su día pudo hacerse $[\ldots]$ pocos caminos eficientes, y todos laboriosos y difíciles, son los que quedan para lograr los fines propuestos de orientar las divisas disponibles como consecuencia de la economía bélica hacia fines de inversión, a efectos de dotar al país con más alto grado de dotación de capital posible [...]. Sólo medidas que tiendan a favorecer la inversión por medios clásicos el espíritu de empresa y, por ende, la inversión privada, son los que parecen brindarse por este momento».

71 Alienes (1949, p. 170).

72 Alienes (1949, p. 171).

73 Dye y Sicotte (2004); Zanetti (2003, p. 151).

74 Dye y Sicotte (2004, p. 698). 
inspiración keynesiana, que pronto se revelaron incapaces de acabar con el estancamiento que sufría el país ${ }^{75}$.

El aumento del gasto público no compensó la descapitalización de la economía cubana ocasionada por la fuga de divisas a Estados Unidos, convertida en un fenómeno ya endémico. Convencidos de que Cuba jamás volvería a disfrutar de las prebendas azucareras y tabaqueras en el mercado mundial, los empresarios declinaron emplear sus beneficios en mejorar sus instalaciones y, desde luego, en colocarlos en la Bolsa. Invertir en Cuba era una pasión inútil, mal retribuida y arriesgada. Hacerlo en La Florida, un valor seguro. Todo lo más, invirtieron en deuda pública, entonces al alza (Gráfico 1). Pero en acciones, ni hablar.

Los propios trabajadores de los centrales culparon al giro en la Bolsa de la depreciación del azúcar y de la pérdida de empleo en el sector, al punto de reclamar la intervención gubernamental. Las dificultades de financiación, fuese en Bolsa o mediante crédito bancario, obligaron a los propietarios de centrales a vender su producto a un precio ínfimo para cubrir, al menos, el gasto corriente, lo que forzaba un descenso de los salarios y del nivel de empleo $^{76}$. El Banco de Desarrollo Económico y Social, última creación financiera de la "República mediatizada», se limitó a comprometer sus recursos en proyectos inútiles, en lugar de hacerlo en un sector que suplicaba lastimosamente numerario ${ }^{77}$.

El escenario cambió bruscamente en 1956, cuando la cotización bursátil registró un repentino aumento (Gráfico 2). Fue tal el resultado de las turbulencias en el mercado azucarero que provocó la segunda guerra árabe-israelí ${ }^{78}$.

Al tiempo, la situación en Oriente Medio desató una auténtica fiebre extractiva en Cuba. Compañías de nuevo cuño subsidiarias de la Esso y la Texaco se empeñaron en buscar recursos petrolíferos por todo el archipiélago que habrían de suplir una parte de las importaciones de los países árabes. Tanto fue así, que las inversiones norteamericanas en la industria petrolera cubana se cuadruplicaron entre 1953 y 1958, hasta alcanzar los 90 millones de dólares $^{79}$. Otro tanto sucedió con las empresas mineras, convencidos sus responsables de la entrada de Estados Unidos en la conflagración tras la proclamación en 1957 de la «doctrina Eisenhower» y, por tanto, de la consiguiente movilización de la producción cubana de níquel, como sucedió a lo largo de la segunda guerra mundial ${ }^{80}$.

Pero no tardó en revelarse la falta de fundamento de estas predicciones, de suerte que los índices bursátiles se desmoronaron a lo largo de 1957 (Gráfico 1).

75 Consejo Nacional de Economía (1956).

76 Biblioteca de la Agencia Española de Cooperación Internacional, Federación Nacional de Trabajadores Azucareros, Actas y Resoluciones, 1954.

77 Mascarós (2003, pp. 103-106).

78 Zuaznábar (1986, p. 62); Dye y Sicotte (2004, p. 698); Zanetti (2003, p. 168).

79 Zuaznábar (1986, p. 51).

80 Zuaznábar (1986, p. 92). 
Los inversores estadounidenses volvieron a desconfiar de Cuba, cuyos valores tuvieron enormes dificultades de colocación a un precio remunerador en la Bolsa de Nueva York. Los sacarócratas tuvieron que conformarse con la escuálida cuota asignada por Estados Unidos en 1956, que les obligaba a incurrir en unos costes fijos medios y de infrautilización del equipo productivo muy elevados ${ }^{81}$. Mermada su competitividad, los norteamericanos se desentendieron de la suerte de la industria azucarera cubana ${ }^{82}$. La de la Bolsa, en 1958, fue todavía a peor.

En plena debacle, y por extraño que parezca, los responsables de la Bolsa depositaron sus esperanzas en el éxito de la Revolución ${ }^{83}$. Incluso el 20 de febrero de 1959, su presidente, Armando Pajarón, invitó al de la República, Manuel Urrutia Lleó, y al primer ministro, Fidel Castro, a visitar sus dependencias. Ellos tenían que hacer de la necesidad virtud; pero los inversores estadounidenses, mucho más perspicaces, no. Noticiosos de lo que sucedía en la isla se desprendieron de sus valores cubanos en cartera tan pronto como tuvieron oportunidad.

No erraron en sus vaticinios. Estas aparentemente buenas relaciones con el Gobierno mudaron en la mayor hostilidad en el verano de 1959, cuando la Revolución adoptó una inspiración nítidamente socialista, lo que trajo consigo el derrumbe de los valores en Bolsa, alimentado por las primeras sanciones comerciales dictadas por Estados Unidos. La mayor parte de las firmas se despidió entonces de la institución. En 1960 solo cotizaron la United Fruit Co., Expreso Aéreo Interamericano, la azucarera Vertientes, y los Almacenes de Regla. En 1961 ya solo lo hicieron las dos últimas de las citadas y la Cuba Rail Road. Inmediatamente después de la abortada invasión de Bahía de Cochinos, en abril de ese año, la Bolsa de La Habana desapareció del panorama financiero cubano, aunque su liquidación formal no se produjo hasta 1970.

El primero de enero de 1959, cuando Batista abandonó el poder, ofrecían sus valores en ella 38 compañías, 11 de las cuales se dedicaban a la elaboración de azúcar. Entre 1910 y 1959, el PIB nominal se había multiplicado por 6,5 y el capital de las empresas cotizadas por 6,2. En otras palabras, nada había cambiado en las relaciones, distantes y ocasionales, entre la gran empresa cubana y la Bolsa en ese medio siglo de existencia.

81 Dye y Sicotte (2004); Dye (1998, pp. 107-118).

82 En 1959 la producción de azúcar en ingenios en manos estadounidenses se cifró en un 20,8\%, cuando en 1939 superó el 55\% (Anuario... 1959, p. 83).

83 «Con ella - escribieron sus responsables - termina uno de los períodos de mayor crisis de la economía, para nacer una época llena de esperanzas en todos los órdenes; pues la honradez administrativa que presida el país, las reformas fiscales y económicas y, sobre todo, el programa que ha expuesto el primer ministro del Gobierno, Fidel Castro Ruz, señalan rumbos de prosperidad para la nación en general y para la Bolsa de La Habana, cuya actividad primordial debe desarrollarse en las transacciones sobre valores industriales» (ANC, Bolsa de La Habana, leg. 10, exp. 11). 


\section{CONCLUSIONES}

La Bolsa de La Habana mostró desde su nacimiento una total sumisión a los dictados del mercado azucarero. Los índices siguieron disciplinadamente el rumbo de la renta per cápita cubana que venía marcado por el precio del azúcar en los mercados mundiales. La consideración en Bolsa de las empresas cubanas quedó por completo al albur de lo sucedido en el tráfico azucarero, estuviesen o no concernidas por él.

La Bolsa de La Habana se caracterizó, con todo, por su escaso recurso como instrumento de financiación que cumplió en su lugar la Bolsa de Nueva York, tanto para la financiación de las grandes azucareras cubanas como para colocar la deuda pública. Tal y como no se cansaron de lamentar sus responsables, en ella apenas cotizaron valores industriales; es decir, no sirvió como ese medio para la diversificación de la economía nacional que se encontró en sus objetivos fundacionales.

Su proyección territorial se limitó a La Habana. No se trata solo de que no llegase a cuajar la creación de una segunda Bolsa en Santiago de Cuba (como pretendía el Gobierno español en 1886) sino de que pocas empresas de oriente del país, o incluso de otros núcleos mercantiles como Matanzas o Camagüey, llegaron a intervenir en la Bolsa capitalina. Grandes firmas como Bacardí, por citar la empresa cubana de mayor proyección exterior en el período, dieron la espalda a la Bolsa, prueba incontrovertible de este desapego.

En realidad, la Bolsa no pasó de herramienta de financiación subsidiaria en años de conflicto bélico en los que las necesidades de suministro de Estados Unidos y los cambios en el mercado mundial posibilitaron lucrativos negocios a los empresarios cubanos.

Por otra parte, la volatilidad y las fuertes fluctuaciones caracterizaron la trayectoria de sus cotizaciones. Esto no solo obedeció a la pequeñez del mercado de valores sino al carácter limitado de las transacciones que allí se efectuaban: pocas, pero rentables.

En suma, la Bolsa mostró los rasgos propios de un intermediario financiero de una economía monoexportadora subdesarrollada. La institución era un engranaje más del círculo vicioso de la pobreza en el que estuvo sumida Cuba durante la primera mitad del siglo XX, sobre todo desde 1934. La institución en nada pudo contribuir a la financiación no onerosa de las empresas del país y, por tanto, a la acumulación de capital, debido a la escasa propensión al ahorro de la población, imputable al bajo nivel de renta y a su reparto social y territorial obscenamente desigual ${ }^{84}$.

La consideración de mis estimaciones (las primeras realizadas con esta prolongación temporal) sobre las cotizaciones de la Bolsa de La Habana, a pesar de su raquitismo, evidencia algunos de los rasgos más retardatarios de

\footnotetext{
${ }^{84}$ Alienes (1950, p. 153).
} 
la estructura económica en el período republicano. Los índices desvelan el carácter dependiente, miope y fugaz de un modelo de crecimiento (que no de desarrollo) solo acaecido en ocasiones en que Estados Unidos se involucró en alguna guerra, la dependencia de las exportaciones de azúcar, declinantes desde 1925, así como la frecuencia con la que el país sufrió vitriólicas fluctuaciones financieras por culpa de la limitada amplitud de su mercado de capitales.

\section{BIBLIOGRAFÍA}

Alienes Urosa, J. (1942): Economía cubana e inversiones internacionales: El mercado de renta fija. La Habana: Sociedad Cubana de Estudios de Seguros.

Alienes Urosa, J. (1949): Economía de post-guerra y desempleo. La Habana: Junta Nacional de Economía.

Alienes Urosa, J. (1950): Características fundamentales de la Economía cubana. La Habana: Banco Nacional de Cuba.

Anuario Azucarero de Cuba. Censo de la industria azucarera de Cuba y manual estadístico nacional e internacional (1959): La Habana: Cuba Económica y Financiera.

Anuario Estadístico de Cuba de 1958. La Habana: Imprenta de P. Fernández y cía.

Banco Nacional De Cuba (1951-1958). Memoria(s). La Habana: Banco Nacional de Cuba.

Betancourt, Á. C. (1909): Código de Comercio vigente en la República de Cuba. La Habana: Imprenta de Rambla y Bouza.

Bulmer-Thomas, V. (2003): The Economic History of Latin America since Independence. Cambridge: Cambridge University Press.

CAzÉ, A. (1861): Tratado completo de cálculo mercantil dividido en tres partes. Barcelona: Librería Plus Ultra.

Collazo Pérez, E. (1994): Una pelea cubana contra los monopolios: (un estudio sobre el crac bancario de 1920). Bilbao: Universidad de Oviedo.

Couyoumdian, J. R. y Tocornal, J. (1983): Historia de la Bolsa de Comercio de Santiago, 1893-1993: un siglo del mercado de valores en Chile. Bolsa de Comercio: Santiago de Chile.

Cuba en la conferencia sobre comercio y empleo. Carta de La Habana (1947). La Habana: Ministerio de Estado.

Cuban investments (1916). Nueva Orleans: Bankers' Loan \& Securities Bank.

DYE, A. (1994): «Cane contracting and renegotiation. A fixed effect analysis of the adoption of new technologies in the Cuba sugar industry, 1899-1929». Explorations in Economic History 31, pp. 141-175.

DYE, A. (1998): Cuban sugar in the age of mass production. Technology and the economics of sugar central, 1899-1929. Stanford: Stanford University Press. 
Dye, A. (2005): "Cuba and the origins of the sugar quota». Revista de Indias 65 (233), pp. 193-218.

Dye, A. y Sicotte, R. (2004): "The U. S. program and the Cuban Revolution». Journal of Economic History 64 (3), pp. 673-704.

Estatuto y reglamento de la sociedad anónima Bolsa Privada de La Habana (1894). La Habana: Imprenta y Litografía La Habanera.

GutiérRez, G. (1952): El desarrollo económico de Cuba. La Habana: Junta Nacional de Economía.

Illán, J. M. (1963): Cuba: datos sobre una economía en ruinas. Miami: (n.d.). JimÉnez Soler, G. (2008): Las empresas de Cuba. 1958. La Habana: Ciencias Sociales.

La estimulación industrial en Cuba (1956). La Habana: Consejo Nacional de Economía.

Le Reverend, J. (1974): Historia Económica de Cuba. La Habana: Ministerio de Economía.

Le Reverend, J. (1975): La República. La Habana: Editorial de Ciencias Sociales.

Lewis, C. M. (2008): «Economías de exportación», en E. Ayala Mora y E. Posada Carbó (dirs.), Los proyectos nacionales latinoamericanos: sus instrumentos y articulación, 1870-1930. París: Unesco, pp. 70-110.

Maddison, A. (1985): Deux crisis: L'Amérique Latine et L'Asie. 1929-38 et 1973-83. París: OCDE.

Marichal, C. (2010): Nueva historia de las grandes crisis financieras. Una perspectiva global, 1873-2008. Barcelona: Debate.

Mcavoy, M. (2003): Sugar baron. Manuel Rionda and the fortunes of pre-Castro Cuba. Gainesville: University Press of Florida.

Meisel Roca, A. (2008): "Mercados internos, industrialización y finanzas», en E. Ayala Mora y E. Posada Carbó (dirs.), Los proyectos nacionales latinoamericanos: sus instrumentos y articulación, 1870-1930. París: Unesco, pp. 111-130.

Memoria presentada por la Junta Directiva a la Junta General de Accionistas (1906). La Habana: Bolsa de La Habana.

Pérez Cubilla, J. M. y Pazos y Roque, F. (1940): El problema monetario de Cuba. La Habana: La Verónica.

Pérez Lavielle, G. (1957): «Las corporaciones económicas brindan un valioso aporte al auge económico de Cuba». Diario de la Marina. Siglo y cuarto. Número Extraordinario. La Habana: Diario de La Marina, pp. 44-56.

Porter, R. P. (1899): Industrial Cuba. Nueva York y Londres: G. P-Putnam's sons/The kmickerbocher Press.

Problemas de la nueva Cuba. Informe de la comisión de asuntos cubanos (1935). Nueva York: Foreign Policy Association Incorporated.

RicARdi, A. (1954): "Medio siglo de vida económica en Cuba». Mundo Hispánico (número especial dedicado a Cuba) 71, pp. 32-35.

Roldán De Montaud, I. (2005): «De banco de gobierno a banco comercial: el Banco Español de la isla de Cuba de la colonia a la República», en 
F. Moulin Civil, (coord.), Regards croisés. Cuba/Espagne $\left(X I X^{e}-X X^{e}\right)$. Vincennes-Saint Denis: Université París VIII,, pp. 61-82.

Roselló, A. A. (1954): El libro de Cuba. La Habana: Tall. Graf. Publicaciones Unidas.

SANTAMARÍA García, A. (1994): «La crisis financiera de 1920-1921 y el ajuste de alza de la industria azucarera cubana». Revista de Historia Industrial 5, pp. 121-148.

Santamaría García, A. (2000): «El crecimiento económico de Cuba Republicana (1902-1959). Una revisión y nuevas estimaciones en perspectiva comparada (población, inmigración golondrina, ingreso no azucarero y producto nacional bruto)». Revista de Indias 60 (219), pp. 505-546.

SANTAMARÍA GARCíA, A. (2002): Sin azúcar no hay país. La industria azucarera y la economía cubana (1919-1939). Sevilla: Universidad de Sevilla/CSIC/ Diputación de Sevilla.

Secretaría De Hacienda (1908-1921): Cotizaciones y operaciones verificadas sobre los valores, acciones y bonos de sociedades, empresas y compañias. La Habana: Imprenta de La Prosperidad.

Truslow, F. A. (1951): Report on Cuba: Findings and recommendations of an economic and technical Mission organized by the International Bank of Reconstruction and Development in collaboration with the Government of Cuba in 1950. Nueva York: International Bank of Reconstruction and Development. VILAR, J. B. (1990): La historia en sus documentos. El despegue de la Revolución Industrial en España, 1827-1869. Madrid: Istmo.

Wallich, H. C. (1950): Monetary problems of an export economy. The Cuban experience, 1914-1947. Cambridge (Massachusetts): Harvard University Press.

Wolter Del Río, G. (1937): Aportaciones para una política económica cubana. La Habana: Úcar, García y cía.

ZanetTI Lecuona, Ó. (2003): Cautivos de la reciprocidad. La burguesía cubana y la dependencia comercial. La Habana: Ciencias Sociales.

Zanetti Lecuona, Ó. y García Álvarez, A. (1987): La United Fruit Co.: Un caso de dominio imperialista en Cuba. La Habana: Ciencias Sociales.

Zuaznábar, I. (1986): La economía en la década del 50. La Habana: Ciencias Sociales. 


\section{APÉNDICE}

\section{CUADRO 1}

AGREGADOS AZUCAREROS CUBANOS (EN MILES DE TONELADAS, DÓLARES CORRIENTES LA LIBRA ESTADOUNIDENSE Y NÚMEROS ÍNDICES BASE 1950)

\begin{tabular}{|c|c|c|c|}
\hline AÑO & EXPORTACIONES & PRODUCCIÓN & PRECIO \\
\hline & Miles de $t$ & Miles t & $\$ / \mathbf{L b}$ \\
\hline 1910 & 1.609 & 1.446 & 2,8 \\
\hline 1911 & 1.374 & 1.159 & 2,0 \\
\hline 1912 & 1.745 & 1.654 & 2,8 \\
\hline 1913 & 2.100 & 2.002 & 2,2 \\
\hline 1914 & 2.130 & 2.081 & 2,8 \\
\hline 1915 & 2.118 & 2.212 & 3,5 \\
\hline 1916 & 2.123 & 2.358 & 4,7 \\
\hline 1917 & 1.944 & 2.522 & 5,2 \\
\hline 1918 & 2.215 & 2.775 & 5,4 \\
\hline 1919 & 3.072 & 3.332 & 6,5 \\
\hline 1920 & 2.301 & 3.027 & 11,3 \\
\hline 1921 & 2.303 & 3.232 & 3,5 \\
\hline 1922 & 2.302 & 3.078 & 3,0 \\
\hline 1923 & 3.011 & 2.789 & 5,2 \\
\hline 1924 & 3.313 & 3.148 & 4,1 \\
\hline 1925 & 3.557 & 4.107 & 2,5 \\
\hline 1926 & 3.697 & 3.848 & 2,5 \\
\hline 1927 & 3.183 & 3.569 & 2,9 \\
\hline 1928 & 2.672 & 3.088 & 2,4 \\
\hline 1929 & 3.477 & 3.764 & 1,9 \\
\hline 1930 & 1.951 & 3.426 & 1,4 \\
\hline 1931 & 1.738 & 2.258 & 1,3 \\
\hline 1932 & 1.227 & 2.088 & 0,9 \\
\hline 1933 & 939 & 1.545 & 1,2 \\
\hline 1934 & 1.279 & 1.746 & 1,4 \\
\hline
\end{tabular}


CUADRO 1 (Cont.)

\begin{tabular}{|c|c|c|c|}
\hline 1935 & 1.330 & 1.960 & 2,3 \\
\hline 1936 & 1.284 & 2.178 & 2,6 \\
\hline 1937 & 1.582 & 2.709 & 2,5 \\
\hline 1938 & 1.441 & 2.301 & 2,0 \\
\hline 1939 & 1.604 & 2.231 & 1,9 \\
\hline 1940 & 1.345 & 2.462 & 1,8 \\
\hline 1941 & 2.203 & 2.579 & 2,4 \\
\hline 1942 & 1.286 & 2.881 & 2,9 \\
\hline 1943 & 2.593 & 1.964 & 2,9 \\
\hline 1944 & 3.046 & 3.574 & 2,9 \\
\hline 1945 & 2.399 & 2.383 & 3,4 \\
\hline 1946 & 2.015 & 3.907 & 4,6 \\
\hline 1947 & 3.240 & 4.147 & 5,4 \\
\hline 1948 & 2.318 & 4.280 & 5,0 \\
\hline 1949 & 2.457 & 3.629 & 5,3 \\
\hline 1950 & 2.445 & 3.701 & 5,4 \\
\hline 1951 & 2.365 & 3.907 & 5,5 \\
\hline 1952 & 2.245 & 5.177 & 5,7 \\
\hline 1953 & 2.247 & 3.548 & 5,7 \\
\hline 1954 & 2.028 & 3.754 & 5,5 \\
\hline 1955 & 2.214 & 3.569 & 5,4 \\
\hline 1956 & 2.383 & 3.481 & 5,5 \\
\hline 1957 & 2.424 & 3.888 & 5,7 \\
\hline 1958 & 2.753 & 4.167 & 5,7 \\
\hline 1959 & & 4.206 & \\
\hline
\end{tabular}

Fuente: Anuario (1959), pássim; y elaboración propia. 


\section{CUADRO 2}

COTIZACIONES DE LA BOLSA DE LA HABANA, (1910-1959) (EN TÉRMINOS NOMINALES Y NÚMEROS ÍNDICES BASE 1950)

\begin{tabular}{|c|c|c|}
\hline AÑO & ACCIONES & DEUDA PÚBLICA \\
\hline 1910 & 225,2 & 71,6 \\
\hline 1911 & 181,1 & 73,3 \\
\hline 1912 & 175,9 & 72,2 \\
\hline 1913 & 162,6 & 63,9 \\
\hline 1914 & 141,8 & 68,1 \\
\hline 1915 & 133,8 & 62,4 \\
\hline 1916 & 256,6 & 61,7 \\
\hline 1917 & 265,5 & 67,0 \\
\hline 1918 & 261 & 67,0 \\
\hline 1919 & 278,5 & 67,0 \\
\hline 1920 & 248 & 49,3 \\
\hline 1921 & 56,1 & 44,5 \\
\hline 1922 & 64,5 & 65,5 \\
\hline 1923 & 204,5 & 53,9 \\
\hline 1924 & 237,7 & 58,5 \\
\hline 1925 & 219,2 & 56,6 \\
\hline 1926 & 208,9 & 61,7 \\
\hline 1927 & 266,2 & 64,0 \\
\hline 1928 & 211,1 & 63,2 \\
\hline 1929 & 199,6 & 66,2 \\
\hline 1930 & 115,5 & 61,9 \\
\hline 1931 & 63,5 & 31,1 \\
\hline 1932 & 34 & 40,4 \\
\hline 1933 & 32,8 & 50,6 \\
\hline 1934 & 33,8 & 31,8 \\
\hline 1935 & 58,1 & 53,6 \\
\hline 1936 & 72,1 & 56,5 \\
\hline 1937 & 53,5 & 60,7 \\
\hline
\end{tabular}


CUADRO 2 (Cont.)

\begin{tabular}{|c|c|c|}
\hline 1938 & 45,8 & 72,2 \\
\hline 1939 & 66,5 & 74,6 \\
\hline 1940 & 69,2 & 54,9 \\
\hline 1941 & 124,3 & 54,2 \\
\hline 1942 & 102,1 & 61,2 \\
\hline 1943 & 187,8 & 68,6 \\
\hline 1944 & 227,1 & 74,1 \\
\hline 1945 & 190,1 & 70,8 \\
\hline 1946 & 231,6 & 79,1 \\
\hline 1947 & 127,2 & 79,0 \\
\hline 1948 & 100,6 & 90,0 \\
\hline 1949 & 87,4 & 94,6 \\
\hline 1950 & 80,8 & 100,0 \\
\hline 1951 & 73,5 & 100,6 \\
\hline 1952 & 74,6 & 101,2 \\
\hline 1953 & 69,3 & 99,2 \\
\hline 1954 & 123,1 & 97,3 \\
\hline 1955 & 121 & 97,3 \\
\hline 1956 & 199,6 & 93,5 \\
\hline 1957 & 127,5 & 91,3 \\
\hline 1958 & 104,4 & 91,3 \\
\hline 1959 & 34,5 & 94,3 \\
\hline
\end{tabular}

Fuente: ANC, Bolsa de La Habana, Actas de Cotizaciones y elaboración propia. 


\section{CUADRO 3}

COTIZACIONES DE LOS VALORES CUBANOS EN L A BOLSA DE NUEVA YORK (1910-1959) (EN TÉRMINOS NOMINALES Y NÚMEROS ÍNDICES BASE 1950)

\begin{tabular}{|c|c|c|c|}
\hline AÑo & OBLIGACIONES & DEUDA EXTERNA & ACCIONES AZUCARERAS \\
\hline 1910 & & & 85,6 \\
\hline 1911 & & & 74,2 \\
\hline 1912 & & & 167,0 \\
\hline 1913 & & & 74,2 \\
\hline 1914 & & & 64,0 \\
\hline 1915 & & & 99,1 \\
\hline 1916 & & & 185,5 \\
\hline 1917 & & & 165,6 \\
\hline 1918 & & & 141,9 \\
\hline 1919 & & & 229,2 \\
\hline 1920 & & & 186,6 \\
\hline 1921 & & & 151,2 \\
\hline 1922 & & & 218,8 \\
\hline 1923 & & & 132,2 \\
\hline 1924 & & & 154,5 \\
\hline 1925 & & & 136,1 \\
\hline 1926 & 100,8 & 64,5 & 178,8 \\
\hline 1927 & 188,4 & 71,0 & 151,4 \\
\hline 1928 & 120,9 & 73,2 & 130,5 \\
\hline 1929 & 53,3 & 71,0 & 93,1 \\
\hline 1930 & 45,2 & 61,0 & 65,8 \\
\hline 1931 & 37,1 & 51,1 & 51,0 \\
\hline 1932 & 16,4 & 37,0 & 77,2 \\
\hline 1933 & 39,0 & 33,5 & 80,0 \\
\hline 1934 & 22,6 & 52,7 & 63,7 \\
\hline 1935 & 62,2 & 68,7 & 63,3 \\
\hline 1936 & 71,1 & 68,8 & 73,6 \\
\hline 1937 & 70,6 & 71,0 & 61,0 \\
\hline
\end{tabular}


CUADRO 3 (Cont.)

\begin{tabular}{|l|c|c|c|}
\hline 1938 & 61,4 & 65,2 & 105,5 \\
\hline 1939 & 69,3 & 65,9 & 87,0 \\
\hline 1940 & 48,9 & 62,4 & 56,8 \\
\hline 1941 & 49,4 & 70,7 & 59,6 \\
\hline 1942 & 63,9 & 70,1 & 62,3 \\
\hline 1943 & 73,6 & 76,4 & 80,5 \\
\hline 1944 & 101,1 & 82,2 & 96,0 \\
\hline 1945 & 97,5 & 85,3 & 130,7 \\
\hline 1946 & 106,8 & 87,4 & 138,0 \\
\hline 1947 & 91,2 & 95,6 & 100,3 \\
\hline 1948 & 72,8 & 86,4 & 92,7 \\
\hline 1949 & 103,5 & 97,6 & 72,0 \\
\hline 1950 & 100,0 & 100,0 & 100,0 \\
\hline 1951 & 96,5 & 102,8 & 110,5 \\
\hline 1952 & 75,6 & 102,8 & 103,5 \\
\hline 1953 & 66,6 & 102,7 & 100,3 \\
\hline 1954 & 57,6 & 102,8 & 97,1 \\
\hline 1955 & 55,6 & 97,2 & 68,1 \\
\hline 1956 & 63,6 & 93,9 & 78,7 \\
\hline 1957 & 56,3 & 102,8 & 80,7 \\
\hline 1958 & 51,6 & 91,8 & 79,4 \\
\hline 1959 & 19,2 & $7 h, 1$ & \\
\hline
\end{tabular}

Fuente: El Diario de la Marina, La Habana y The New York Tribune, Nueva York. 